\title{
Effect of Organic Loading on Biogas Yields from Continuous Semi-dry Fermentation of Swine Manure
}

\author{
LI Qing, TAN Yanping, MA Jing, HU Jian \\ College of Water Conservancy and Hydropower \\ Engineering \\ Sichuan Agricultural University \\ Ya'an, China \\ e-mail: lq87416@126.com
}

\author{
CHEN Chuang \\ Biogas Institute of Ministry of Agriculture \\ Chengdu, China
}

\begin{abstract}
Down pushed flow anaerobic reactor (DPAR) was adopted in the paper to reveal the yielding gas process by taking swine manure as the material under different volume organic loading $\left(3.11,4.44,5.78\right.$ gTS.L $\left.\mathrm{L}^{-1} . \mathrm{d}^{-1}\right)$ and to detect the optimal volume organic loading for semi-dry fermentation of swine manure. The results indicate that: The higher the organic loading, the higher volume gas productivity, while the lower biogas production velocity of the material will be. The change of organic loading has few aggregate impacts on ammonia nitrogen. Besides, due to long duration of acclimation, the tolerance of microorganism will be significantly enhanced. The preferred organic loading for semidry fermentation of swine manure with DPAR is 4.44gTS.(L.d) 1 .
\end{abstract}

Keywords-swine manure; semi-dry fermentation; organic loading; ammonia nitrogen

\section{INTRODUCTION}

Biogas fermentation, as an important method of largescaled piggery wastes treatment, is dually efficient on environmental protection and energy resource recovery. Volume organic loading is an essential parameter for biogas engineering design and running. It refers to the amount of organic matters undertook by per unit volume of digestive apparatus per day. Volume organic loading is associated with factors such as temperature, raw material and process. However, most researchers believed that generally the volume organic loading of swine manure wet fermentation will not exceed $4.0 \mathrm{~kg} \mathrm{CODm}^{-3} \mathrm{~d}^{-1}$, which is the upper limit of designed load for engineering oriented swine manure wet fermentation [1-3]. IC process can improve feed loading of swine manure. However, since the internal structure of IC reactor is complicated, may issue on design and management exist during the application process [4]. How to improve the load rate of reactor and to minimize the device volume need to be urgently solved for swine manure biogas fermentation process. To this end, dry fermentation of swine manure which is characterized of water conservation and convenient biogas residue treatment seems to be indispensable. The process can improve the utilization rate of equipment, as well as reduce the investment and running costs through increasing feed concentration
(TS>20\%), reducing hydraulic loading and increasing volume organic loading.

At present, there are few researches and reports on semi-dry fermentation organic loading of swine manure at abroad. Moreover, most of the existing researches are concentrated on batch fermentation process of mixture material [5-6]. Due to the bottlenecks [7] on the reactor leakproofness and rapid material loading \& discharging during batch fermentation process, as well as the simplicity of biogas engineering materials in domestic market, cofermentation is not suitable for domestic piggery wastes treatment [8]. The research adopted DPAR to reveal the yielding gas process by taking swine manure as the material. The research results demonstrate that swine manure continuous fermentation process is feasible [9]. However, there is no research on volume organic loading on biogas yields from continuous semi-dry fermentation of swine manure at present. Consequently, to study the yielding gas process from continuous semi-dry fermentation of swine manure at different volumes, and to detect the optimal volume organic loading for semi-dry fermentation of swine manure have important significance on improving the utilization rate of dry fermentation device and continuous dry fermentation performance.

\section{Materials AND Method}

\section{A. Test device}

As shown in Figure 1, the test adopted self-made anaerobic reactor (volume: 5L, effective volume: 4.5L) with swine manner on the top and discharge outlet at the bottom. Water bath circulation heat preservation is utilized on the exterior wall of the reactor.

\section{B. Test material}

Fresh swine manure with TS of $24.3 \%$ was resourced from a piggery in Sichuan. The inoculated sludge was from anaerobic digestion sludge of the laboratory. Main physic and chemical properties of the swine manure and sludge are as shown in Table I. 


\section{Experiment design and analytical method}

Three reaction units were adopted, respectively R1, R2 and R3. The setting temperature is $25^{\circ} \mathrm{C}$. The organic loading adopted respectively is $\mathrm{R} 1=3.11 \mathrm{~g} / \mathrm{L} . \mathrm{d}-1, \mathrm{R} 2=4.44 \mathrm{~g} / \mathrm{L} . \mathrm{d}-1$, R3=5.78g/L.d-1. After test start-up, overall sludge inoculation was adopted (namely filling 4.5L inoculated sludge with TS of $13.3 \%$ in three fermentation cylinders). Carry out discharging first and then loading, direct fresh swine manure loading (TS=24.3.1\%). The wet weight of materials are R1=57.6g, R2= 82.2g and R3=107g respectively(shown in Table II). The wet weight of loading and discharging are equal.

At test running process, record the biogas yield, and $\mathrm{PH}$ value of discharging once every day. Record discharging TS and NH4+-N once per every two days. After gas collecting bag (volume 13L) collecting biogas, measure the gas composition. After 60d, all indicators will stabilize and stop the test. The biogas yield is measured by adopting wet gas flow meter (rated flow $0.2 \mathrm{~m} 3 / \mathrm{h}$, model LML-1, Changchun Automotive Filter Co., Ltd.) Biogas ingredient is determined by using biogas composition analyzer
(ADOS.BIOGAS.GA); and the PH value is determined by pHS-3C+ acidimeter. TS, VS are determined by adopting gravimetric method. UV nessler's reagent spectrophotometry is adopted by NH4+-N [10] (spectrophotometer is THERMO heliso alpha 100-240, SHIMADZU UV-2450).

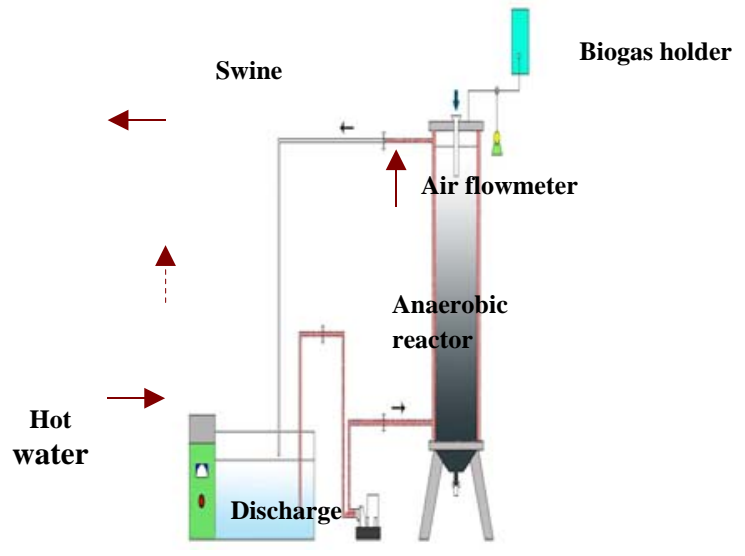

Figure 1. Schematic diagram of anaerobic reactor

table I. Main Physical and Chemical Properties of the Materials Used in the Test

\begin{tabular}{|c|c|c|c|c|c|c|c|c|c|}
\hline \multicolumn{2}{|c|}{ Material } & pH & TS/\% & VS/TS/\% & $\mathrm{NH}_{4}{ }^{+}-\mathrm{N} / \mathrm{mg} \cdot \mathrm{L}^{-1}$ & TKN/TS/\% & Organic matter $/ \mathrm{TS} / \%$ & TC/TS/\% & $\mathbf{C} / \mathbf{N}$ \\
\hline \multirow{2}{*}{\multicolumn{2}{|c|}{$\begin{array}{c}\text { Swine manure } \\
\text { Inoculated sludge }\end{array}$}} & 7.32 & 24.3 & 77.9 & 400 & 2.28 & 56.8 & 32.9 & 14.5 \\
\hline & & 8.1 & 13.3 & 57.1 & 2456 & 2.37 & - & - & - \\
\hline & & & & TABLE II. & \multicolumn{5}{|c|}{ Operating Parameters of Three Reactors } \\
\hline Device & \multicolumn{2}{|c|}{ Loading TS/\% } & \multicolumn{2}{|c|}{ Temperature $/{ }^{\circ} \mathrm{C}$} & \multicolumn{2}{|c|}{ Volume organic loading/gTS.L $L^{-1} . d$} & \multicolumn{3}{|c|}{ Wet weight of swine manure loading/g } \\
\hline R1 & \multicolumn{2}{|c|}{24.3} & \multicolumn{2}{|r|}{$25 \pm 2$} & \multicolumn{2}{|c|}{3.11} & \multicolumn{3}{|c|}{57.6} \\
\hline R2 & \multicolumn{2}{|c|}{24.3} & \multicolumn{2}{|r|}{$25 \pm 2$} & \multicolumn{2}{|c|}{4.44} & \multicolumn{3}{|c|}{82.2} \\
\hline R3 & \multicolumn{2}{|c|}{24.3} & \multicolumn{2}{|r|}{$25 \pm 2$} & \multicolumn{2}{|c|}{5.78} & \multicolumn{3}{|c|}{107} \\
\hline
\end{tabular}

III. TEST RESULTS AND DISCUSSION

A. Effect of organic loading on biogas production velocity

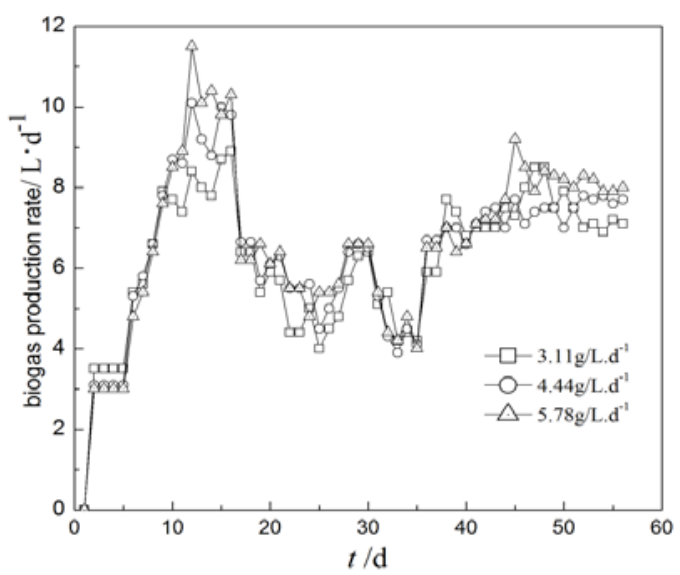

Figure 2. Change of biogas production rate under different organic loading
As shown in Figure 2 , under $25^{\circ} \mathrm{C}$ and active reactor volume of 4.5L, a high concentration of sludge inoculation was adopted to perform swine manure consecutive dry fermentation. The test started very quickly without acidification phenomenon. This is because that there is great amount of microorganism generating methane in high concentration sludge. At early stage of the reaction, small molecular substances generated at acidifying phase can rapidly generate biogas. Under diversified organic loading, the biogas production rate of three reactors (R1, R2 and R3) can reach the top value, namely $8.00,9.58$ and $10.4 \mathrm{~L} \cdot \mathrm{d}^{-1} .15$ days after the project starting up. Along with the process of the reaction, biogas production rate will start dropping along with the accumulation of ammonia nitrogen under three organic loading conditions. At this moment, the accumulated concentration of ammonia nitrogen under different organic loading conditions (R1, R2 and R3) are 2867, 3010 and $2998 \mathrm{mg} \cdot \mathrm{L}^{-1}$. The biogas production rate starts dropping. The accumulated concentration of ammonia nitrogen is obviously higher than the initial inhibition concentration at temperature test process $(2300 \mathrm{mg} \cdot \mathrm{L}$ 
$\left.{ }^{1}\right)$. This is because that the inoculated sludge is sludge of high ammonia nitrogen concentration after test of acclimation. The system can withstand the higher concentration of ammonia nitrogen. Under the condition of high concentration of ammonia nitrogen, after 25 days of biogas inhibition, the biogas production rate of three reactors starts rising around 40 days. After the test lasting for 50 days, the biogas production rate of R1, R2 and R3 trend to be stable with biogas production rate of 7.06, 7.72 and $8.06 \mathrm{~L} \cdot \mathrm{d}^{-1}$. From the point of the whole test process, the volume gas productivity of R2, R3 are not great, only as $4.4 \%$. Under the same test conditions, the biogas production rate of R2 and R3 are obviously higher than $\mathrm{R} 1$.

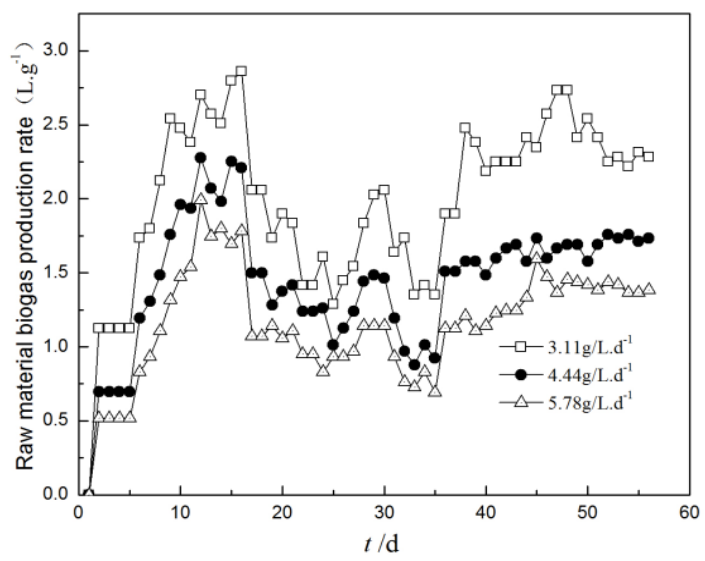

Figure 3. Under different organic loading, raw material biogas production rate of swine manure

For biogas fermentation test under different organic loading conditions, not only the biogas production velocity has to be considered. The utilization efficiency of raw material can be manifested through raw material gas yield. As shown in Figure 3, under different organic loading conditions, raw material gas yield experienced rising first, dropping later and rising balance. The variation tendency and biogas production velocity are basically the same. The difference is that the higher the biogas production velocity, the lower gas yield rate will be. After gas production balance, the gas yield rates of R1, R2 and R3 are respectively are $2.30,1.71$ and $1.38 \mathrm{~L} \cdot \mathrm{d}^{-1}$, it is because that increasing rate is far from achieving the increasing rate of organic loading (30\%). Therefore, the increasing of organic loading will lead to increasing of biogas production velocity. It cannot fully explain gas production performance of swine manure biogas fermentation. Thus, combining with biogas production velocity and gas yield rate, the preferred organic loading for dry fermentation of swine manure is 4.44gTS. $\mathrm{L} \cdot \mathrm{d}^{-1}$.

\section{B. Effect of organic loading on discharging $\mathrm{PH}$}

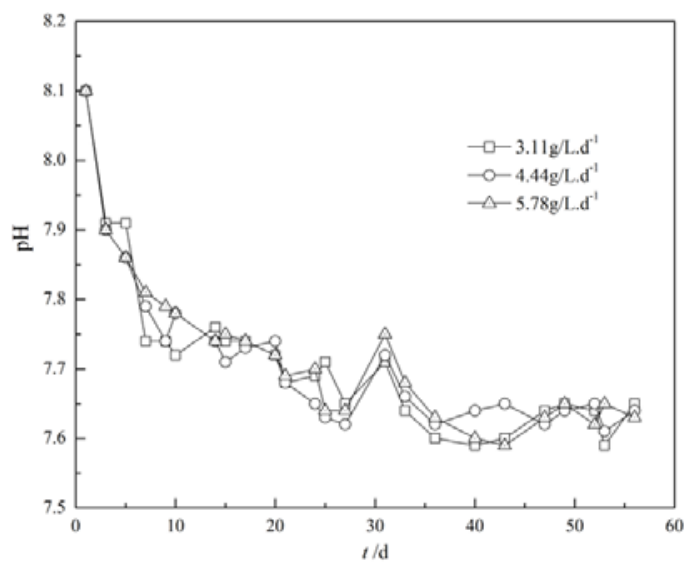

Figure 4. Under different organic loading, variation of discharging PH value

As shown in Figure 4, $\mathrm{PH}$ value variation tendency under organic loading adopted in the test are basically the same. With the process of loading, acidifying hydrolysis of raw materials, and $\mathrm{PH}$ value in the three reactors start reducing. Around 30 days, with raw material degradation and accumulation of ammonia nitrogen, the $\mathrm{PH}$ value in the three reactors presents a brief rising. 35 days later, due to steady acid base balance in the reaction system, the $\mathrm{PH}$ value of three reactors starts keep stable at 7.5, 7.6 and 7.6. While keeping the temperature at $25^{\circ} \mathrm{C}$, from the variation of discharging $\mathrm{PH}$ value under different organic loading, it can be seen that the organic loading adopted in the test has small effect on $\mathrm{PH}$ value of swine manure consecutive dry fermentation. In addition, $\mathrm{PH}$ value can maintain appropriate growth range in anaerobic microorganisms.

\section{Effect of organic loading on concentration of discharging ammonia nitrogen and dissociated ammonia}

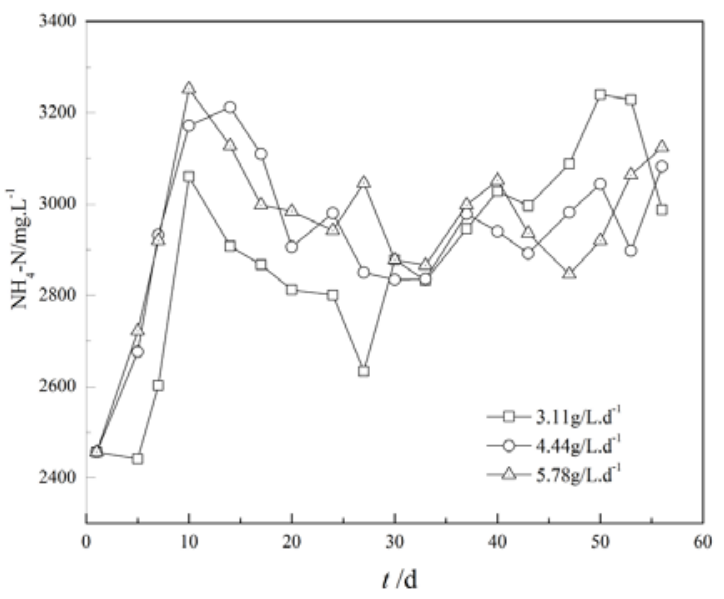

Figure 5. Variation of discharging ammonia nitrogen under different organic loading conditions 


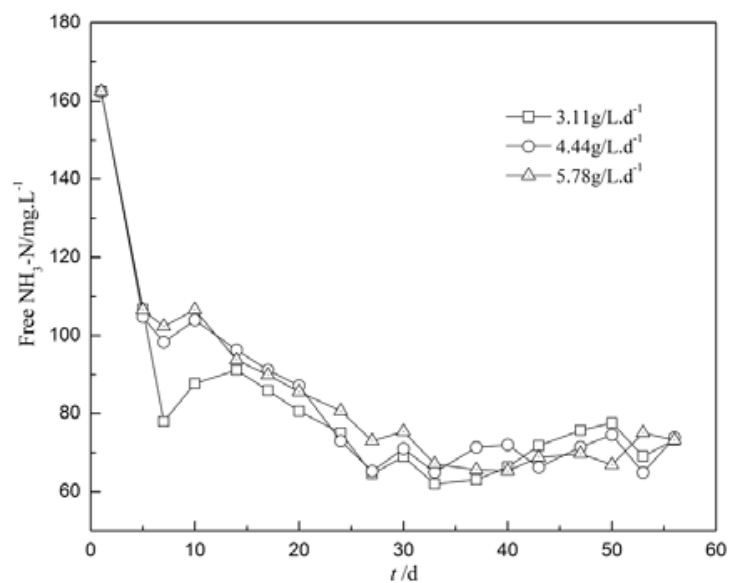

Figure 6. Variation of discharging free ammonia nitrogen concentration under different organic loading conditions

Ammonia is mainly composed of protein and urea decomposition. Due to the high content of nitrogen in swine manure, ammonia inhibition is a factor that should be taken into consideration during the biogas production process. Figure 5 shows the ammonia nitrogen content variation curve generated from swine manure dry fermentation under different organic loading conditions. In case of very low ammonia nitrogen concentration, it has certain acceleration effects on microorganism activity. With the increasing of the concentration, it will cause inhibiting effect. The higher concentration, the stronger inhibiting effect will be. In the test, the initial concentration of ammonia nitrogen is 2456 $\mathrm{mg} \cdot \mathrm{L}^{-1}$, which has reached the minimum inhibition concentration specified in many research literatures about anaerobic digestion. However, the biogas production velocity of the three reactors will not be inhibited due to tolerance of microorganism to the high concentration of ammonia nitrogen caused by long duration of acclimation. With the loading undergoing, the ammonia nitrogen mass concentration in R1, R2 and R3 can reach the first accumulated peak, namely 2908, 3172 and $3252 \mathrm{mg} \cdot \mathrm{L}^{-1}$. The higher organic loading, the higher accumulated concentration of ammonia nitrogen will be. At this moment, the inhibition phenomenon occurred and the biogas production velocity decreased (Figure 3), the degradation rate of material started to decrease as well. The accumulated concentration of ammonia nitrogen started to decrease. At about day 30, the ammonia nitrogen mass concentration in $\mathrm{R} 1, \mathrm{R} 2$ and R3 dropped to $2800 \mathrm{mg} \cdot \mathrm{L}^{-1}$. And then due to adaption of microorganism to the high ammonia nitrogen concentration, Biogas production velocity started to recover (Figure 3). The accumulative concentration of ammonia nitrogen increased correspondingly (Figure 5). After day $40 \sim 50$, the ammonia nitrogen concentration in the three reactors reached the second accumulative peak and maintained at 3000 3200 $\mathrm{mg} \cdot \mathrm{L}^{-1}$. In addition, the lower the loading, the higher accumulated concentration of ammonia nitrogen will be. From the whole reaction process it can be seen that under different organic loading conditions, the mass concentration of ammonia nitrogen accumulated at different reaction time phases are different. However, the general tendency is that it presents slight increasing along with the increasing of organic loading.

Free ammonia has excellent membrane permeability. Among the four types of anaerobic floras, methanogens are mostly prone to be inhibited by ammonia nitrogen to stop growth which is the primary cause for decreasing of anaerobic digestion gas yield. Curves of free ammonia concentration under different organic loading can be calculated relying on the free ammonia nitrogen concentration calculation formula [11] as shown in Figure 6. Under different organic loading conditions, the difference on mass concentration of free ammonia is not great. The variation tendency is basically the same as well. From the whole reaction process, with the $\mathrm{PH}$ value decreasing from 8.1 to $7.5 \sim 7.6$ at the completion of the test in the three reactors, the concentration of free ammonia also decreased from $162.4 \mathrm{mg} \cdot \mathrm{L}^{-1}$ to $70 \mathrm{mg} \cdot \mathrm{L}^{-1}$.

\section{ConcLusion}

While taking swine manure as the material of anaerobic fermentation and combining with biogas production velocity and gas yield rate, the preferred organic loading for dry fermentation of with DPAR swine manure is $4.44 \mathrm{~g} / \mathrm{L} . \mathrm{d}^{-1}$ under constant temperature of $25^{\circ} \mathrm{C}$.

The accumulated concentration of ammonia nitrogen in the three reactors remains 3000 3200 $\mathrm{mg} \cdot \mathrm{L}^{-1}$, under which gas production can undergo smoothly. It turned out that biogas production velocity, percentage composition of methane and accumulated concentration of ammonia nitrogen present inverse ratio. The change of organic loading has few aggregate impacts on ammonia nitrogen. Besides, due to long duration of acclimation, the tolerance of microorganism will be significantly enhanced.

\section{REFERENCES}

[1] J.B. Guo, R.J. Dong, and H.C. Cheng, "Effects of temperature and organic loading on swine manure anaerobic fermentation process," Transactions of the CSAE, vol.27, pp.217-222, Dec 2011.

[2] E. Sanchez, R. Borja, L. Travieso, A. Martin, M. Colmenarejo, "Effect of organic loading rate on the stability, operational parameters and performance of a secondary upflow anaerobic sludge bed reactor treating piggery waste,” Bioresour. Technol, vol. 96, pp.335-344, Mar 2005.

[3] Ministry of Agriculture of the People's Republic of China. "Agricultural industry standard issued by the Ministry of Agriculture of the People's Republic of China," Technical code for biogas engineering. NY/T.1220.1-2006.

[4] J. Zhang, Y.N. Liu, and Z.B. Hu, "Startup behavior research of IC reactor on swine manure waste water treatment," Journal of AgroEnvironment Science, vol.23, pp.777-78, Apr 2004.

[5] X.M. Ye, and Z.Z. Chang, "Literature review on organic solid waste semi-dry anaerobic fermentation technology,” Journal of ecology and rural environment, vol.24, pp.6-79, 96 Feb 2008.

[6] K.J. Chae, J. Am, S.K. Yim and I.S. Kim, “The effects of digestion temperature and temperature shock on the biogas yields from the mesophilic anaerobic digestion of swine manure,” Bioresour. Technol, vol.9, pp.1-6, Jan 2008. 
[7] G.Y. Chen, Z. Zheng, and X.X. Zou et al "Hybrid anaerobic digestion of straw and swine manure," Journal of Agro-Environment Science, vol.28, pp.185-188, Jan 2009.

[8] F.H. Wang, W.Q. Ma, and Z.X. Dou et al "Estimation of livestock manure in China and environment effect," China Environmental Science, vol.26, pp. 614-617. May 2006.

[9] Y. Cheng, Z.Z. Chen, and H.J. Gong et al, "Effect of agitation on swine manure semi-dry method on biogas production," Journal of Anhui Agricultural Sciences, vol.34, pp.17021-17022, 17054, May 2009.
[10]K.H. Hansen, I. Angelidaki, B.K. Ahring, "Anaerobic digestion of wine manure: inhibition by ammonia,” Water Research., vol.32, pp. 512, Jan 1998.

[11] State Environmental Protection Administration, "Water and wastewater monitoring method editorial board, water and exhausted water monitoring and analysis method (Rev. IV)," Beijing: China Environmental Science Press, 2002. 